\title{
LA CONCEPCIÓN GUBERNAMENTAL DEL DESARROLLO LOCAL EN CUBA: DÉFICITS Y LIMITACIONES
}

\author{
Indira Betancourt López \\ Instituto Interuniversitario de Desarrollo Local \\ Universitat de València \\ E-mail: indira.betancourt@uv.es
}

Fecha de recepción: 12/09/2015

Fecha de aceptación: 01/02/2016

\begin{abstract}
Resumen
Cuba presenta una realidad política, económica y social que en gran medida dificulta la aplicación de políticas de desarrollo local. Esto se debe, fundamentalmente, al centralizador poder estatal; el que impide no sólo la puesta en marcha de novedosos diseños de proyectos locales, sino que además impide a algunos de sus propios organismos llevar a término tal cometido. El gobierno revolucionario instaurado en 1959 tuvo entre sus primeras medidas reducir la capacidad jurídica de los municipios. En la década del '90, luego del derrumbe del campo socialista, el gobierno redirigiósu política económica para garantizar su supervivencia en el mundo capitalista. La reforma implicó serias alteraciones en la doctrina estatal comunista.En ella se prioriza, como norma, la política económica y social nacional frente a la local. Una realidad que pudiera ser transformada tomando en consideración los diversos estudios que se han realizado al respecto.
\end{abstract}

Palabras clave: Cuba, descentralización, reforma político-económica, organismos estatales, actores locales, gobierno, municipios

\section{CONCEPTION OF LOCAL GOVERNMENT DEVELOPMENT IN CUBA: DEFICITS AND LIMITATIONS}

\section{Summary}

Cuba presents a political, economic and social reality, which greatly hinders the implementation of local development policies. This is due, mainly, to the centralized state power, which not only prevents the launch of new designs of local projects, but, also, impedes some of its own institutions to complete such task. The revolutionary government that established in 1959 had, among its first measures, reducing the legal capacity of the municipalities. In the 90s, after the collapse of the socialist bloc, the government redirected its economic policies to ensure their survival in the capitalist world. The reform involved serious alterations in the communist state doctrine in which it is prioritized, as a regulation, the national economic and social policy versus the local one. A reality that could be transformed taking into consideration the various studies, which have been done about that. 
Key words: Cuba; decentralization; political and economic reform; state agencies; local stakeholders; government; municipalities.

\section{CONCEPTION DU DÉVELOPPEMENT DES ADMINISTRATIONS LOCALES EN CUBA: DÉFICITS ET LIMITATIONS.}

\section{Résumé.}

Cuba a une réalité politique, économique et social qui entrave considérablement la mise en œuvre de politiques de développement local. Cela est dû principalement à la centralisation du pouvoir de l'État; qui non seulement empêche le lancement de nouveaux modèles de projets locaux, mais empêche également certains de ses propres agences à remplir cette tâche. Le gouvernement révolutionnaire créé en 1959 a été parmi les premières mesures de réduction de la capacité juridique des municipalités. Dans les années 90 , après l'effondrement du bloc socialiste, le gouvernement redirigé ses politiques économiques pour assurer leur survie dans le monde capitaliste. La réforme implique de graves altérations dans la doctrine de l'État communiste. II est prioritaire, en règle générale, la politique économique et sociale nationale par rapport local. Une réalité qui pourrait être transformé en tenant compte des diverses études qui ont été faites à ce sujet.

Mots-clés: Cuba, la décentralisation; la réforme politique et économique; les organismes d'État; les acteurs locaux; le gouvernement; les municipalités

\section{INTRODUCCIÓN}

Las investigaciones sobre desarrollo local llegadas a Cuba desde Europa y América Latina han tenido una importante impronta en el mundo académico de la República a través de diversas vertientes del conocimiento en el último decenio. Los avances se pueden apreciar en investigaciones publicadas, en la defensa de tesis de maestría y doctorado y en la creación de centros de estudios de desarrollo local en occidente, centro y oriente del país. A pesar de ello, en la práctica, esta temática continúa siendo una asignatura pendiente para los académicos y docentes, en tanto constituye un verdadero reto replicar aquello que pueda adecuarse a la compleja realidad de un país que difiere de la mayoría de los Estados del mundo -sino todos-, en cuanto a sus estructuras de funcionamiento, a sus dinámicas políticas y a la concentración de poder legislativo y ejecutivo en escasas instancias del gobierno central.

Como sabemos, tanto las definiciones como las conceptualizaciones del desarrollo local presentan las lógicas diferencias geográficas $y$, además, mutan con el paso del tiempo. Paralelamente, el contexto histórico y su evolución son dos variables imprescindibles para que podamos comprenderlas (Pike, Rodríguez y Tomaney, 2011). Por eso, cuando nos enfrentamos al análisis del desarrollo local de un país tan singular como Cuba, es necesario no solamente atender, por ejemplo, a la extrema complejidad de las estructuras de poder de la isla, sino que debemos atender obligatoriamente a lo que ha sido y es ese contexto histórico que sufrió un cambio radical -realmente revolucionario- a raíz de la victoria de una guerrilla insurgente comandada por un entonces joven abogado 
llamado Fidel Castro Ruz. Han pasado cincuenta y seis años desde aquel primero de enero de 1959, y contra todo pronóstico resiste como una fortaleza sitiada.

Para poder explicar, de manera claramente comprensible para el lector, tanto la definición como la conceptualización del desarrollo local en la República de Cuba es necesario referir de forma muy sintética lo que ha sido la evolución histórica del proceso que llamamos Revolución Cubana, aquél que arranca del sexenio 1953-1959 en su fase insurreccional, y nos lleva a esas más de cinco décadas mencionadas y que abarca desde 1959 hasta nuestros días ${ }^{1}$.

\section{APUNTES NECESARIOS PARA COMPRENDER EL PROCESO HISTÓRICO CUBANO}

A partir de la instauración del gobierno revolucionario, tomando como punto de partida el proceso de institucionalización y la implementación de las directrices políticas de los '60, podemos hacer una periodización que se divide en cuatro etapas fundamentalmente. $L a$ primera etapa, que comprende los años 1959-1962, en los que se establece el carácter socialista de la Revolución, tanto en lo pragmático como en lo programático (Alcázar, 2003: 277-279).

Es el periodo en el que son aplicadas leyes de un fuerte carácter nacionalista y popular, durante el cual comienzan a emerger posiciones abiertamente violentas contra la Revolución. Un ejemplo de ello lo tenemos en la invasión por Bahía de Cochinos, protagonizada por cubanos exiliados desafectos (financiados por el gobierno norteamericano) a la ideología que comenzaba a imperar. Fue una época de tensiones políticas y militares de alcance internacional que desembocará en la Crisis de los Misiles, en 1962.

Entre 1959 y 1960, en el orden económico, se asiste a la liquidación de las estructuras del capitalismo y su mercado. Se experimenta un aumento moderado de la actividad económica junto a una política de gastos controlada por el Estado. Se comienzan a buscar nuevos mercados (en realidad uno solo: el soviético) frente a la negativa del gobierno de los Estados Unidos de mantener el intercambio, como consecuencia del proceso de nacionalización del que se había considerado el principal perjudicado. Un año después, entre 1961 y 1963, se pone en marcha el modelo ortodoxo ruso sobre la planificación central como primera respuesta gubernamental a la crisis económica que se generó en la isla durante esos años.

La segunda etapa va de 1962 a 1971. Son los años en los que se crea la base institucional, ideológica, política, militar y económica de la Revolución. Son creadas

\footnotetext{
${ }^{1}$ La bibliografía sobre ese proceso histórico que llamamos Revolución cubana es inagotable. Obviamente no hemos tenido la menor intención de exhaustividad, pero es necesario indicar por si el lector lo desea que, además de los textos que se citan expresamente, debemos referir dos, uno realizado desde dentro de Cuba y en sintonía con el régimen como es Guerra, S. y Maldonado A. (2009. Historia de la Revolución cubana, Tafalla, Txalaparta; y otro, de una factura completamente distinta y en absoluto complaciente con el sistema castrista, como es el de Marifeli Pérez-Stable, y su obra ya clásica La Revolución cubana. Orígenes, desarrollo y legado. Editorial Colibrí, Madrid, 1998. El primero, absolutamente acrítico y en extremo laudatorio con el castrismo posee, eso sí, un repertorio bibliográfico muy notable recogido entre las entre las páginas 153 y 168. El de Pérez-Stable es la mejor monografía que conocemos sobre el tema.
} 
entidades tales como: el Instituto Nacional de Reforma Agraria (INRA), el Ministerio de las Fuerzas Armadas (MINFAR), o los Comités de Defensa de la Revolución (CDR). Cada uno de ellos colaboró como órgano consultivo pero sin facultad decisoria dentro del gobierno.

Entre 1964 y 1966 se generó un amplio debate y se realizaron muchos estudios en torno a distintos modelos socialistas alternativos. Se observó un incremento económico paulatino pero sostenido, a raíz de las ventajosas condiciones económicas que ofrecía el comercio con el área soviética. El crecimiento económico, en ésta etapa, fue lento ${ }^{2}$.

Fue éste un periodo de falta de consenso en la directriz económica a seguir; fundamentalmente, se debatían entre el seguidismo soviético o la autonomía económica. En otras palabras, las posiciones estuvieron divididas entre los partidarios del conocido cálculo económico y aquellos que estaban a favor del sistema presupuestario de financiamiento.

El cálculo económico brindaba una amplia autonomía a la gestión de las empresas y se valía de las relaciones mercantiles entre ellas, utilizando la ganancia como indicador fundamental para medir la eficiencia económica; por lo que se le otorgaba un papel determinante a la Ley del Valor y al mercado, potenciando el empleo mediante los estímulos materiales o incentivos económicos como principal arma para lograr una mayor productividad de los trabajadores ${ }^{3}$. No obstante, el modelo que se asume entre 1966 y 1970 es el sugerido por el Comandante de la Revolución Ernesto Guevara. Éste sostenía la conveniencia del sistema presupuestario de financiamiento, cuyas características fundamentales eran la centralización de la dirección y la gestión económica, la subestimación de la ley del valor y de sus relaciones mercantiles. En su lugar proponía la utilización del costo de producción como indicador básico de la eficiencia económica, así como el empleo de los estímulos morales como catalizador propicio para lograr la eficiencia económica (Cantón y Navarro, 2009).

La primera consecuencia de la aplicación de éste modelo fue la parálisis del crecimiento económico y el aumento de la dependencia del intercambio comercial con Europa del Este, pues Cuba se vio obligada a entrar completa y definitivamente en la órbita soviética, en el año 1970. "El colapso y el abandono de la experiencia guevarista llegó con el fracaso de la gran zafra de los diez millones de toneladas de azúcar de 1970" (Alcázar, 2003: 279).

Frente al revés económico, a partir de ese año el debate fue dirigido a favor de la aplicación del modelo de cálculo económico. Éste fue el que se tomó como base en 1975 para poner en marcha el sistema de dirección de la economía. Aun así, se reglamentó que debía ser un sistema en consonancia con las condiciones concretas de la isla, e incorporó de forma definitiva el incentivo moral propuesto por Guevara y la emulación comunista en el trabajo.

La tercera etapa se desarrolló entre 1971 y 1985. Son los años en los que se produce la Institucionalización definitiva de los organismos políticos y culturales, con el

\footnotetext{
${ }^{2}$ Al decir de Cantón y Silva (2009), entre 1961-1965, el Producto Social Global aumentó sólo a un ritmo del 1,9\% anual, y entre 1966-170 mejoró unos puntos al llegar al 3,9\%.

${ }^{3}$ El economista más destacado, defensor de éste sistema fue Carlos Rafael Rodríguez (importante político, que ocupó varios cargos de relevancia en la dirección del país).
} 
objetivo de dar cuerpo legal a todas las pautas ideológicas que se habían incorporado y fortalecido por más de dos décadas, pero que todavía carecían del necesario respaldo jurídico. En 1975 se celebró el I Congreso del Partido Comunista de Cuba, y en 1976 se aprobó una nueva Constitución, en sintonía con el sistema socialista instaurado.

En el orden económico se introduce el modelo soviético de reforma económica moderado. Se percibe una sostenida recuperación con unas tasas de crecimiento que fueron las mejores de toda la etapa previa al derrumbe del campo socialista. Aunque también fue la etapa en la que comienza a aparecer el déficit presupuestario. Paralelamente, comienza a apreciarse la paulatina decadencia económica al interior de la URSS.

La cuarta etapa comprende los años de 1986 a 1993. Al tiempo que en la Unión Soviética se implementaba un programa de reformas conocido como Perestroika, en Cuba se puso en marcha el Proceso de rectificación de errores y tendencias negativas. Todo ello con el objetivo de subsanar aquellos fallos detectados que obstaculizaron y afectaron a distintos sectores de la sociedad civil y a la población, así como con el de conseguir una mayor eficiencia económica.

A partir del año 1991se produjo la crisis económica más importante de la historia del país, como consecuencia de la desaparición absoluta de los subsidios de Moscú a la isla debido al colapso que sufrió la URSS. En todos los órdenes, ésta fue la peor etapa de la Revolución, tanto en materia económica como social y política. Las más evidentes de las consecuencias económicas fueron el aumento exponencial de la masa monetaria, un abultado déficit presupuestario y que el proceso de industrialización sufriera un serio revés.

De 1993 hasta los albores del siglo XXI, el país transitó por los años más duros de su historia; una etapa conocida como el Periodo Especial. Sus consecuencias se pueden resumir en el racionamiento más estricto de los productos alimenticios y de primera necesidad, así como en los sucesivos y frecuentísimos cortes de fluido eléctrico (apagones) producidos por la escasez de petróleo. Una etapa de creciente miseria y hambre, en la que "como contrapartida, la población recurrió al único remedio que le quedaba, la inventiva, mientras que el gobierno cubano aumentaba el control estatal y la centralización de la economía" (Alcázar, 2003: 279).

Desde entonces, existen datos sobre la mendicidad, sobre el desempleo, los barrios marginales, el juego, las drogas, el alcoholismo y la prostitución que reaparecieron en la isla (Alcázar, J. y Rivero, S. 2013: 15). Al margen de los datos de la oficialidad relacionados con el resurgimiento de estos males sociales, los indicadores muestran que, en 1993, los gastos sociales decrecieron en un $73 \%$, sin grandes cambios hasta el año 1998 , en el que aún el gasto estaba por debajo del $40 \%$ del que hubo en 1989 . En otras palabras, la desigualdad aumentó en un 69\% entre los años 1989 y 1999.

El informe del PNUD sobre el Índice de Desarrollo Humano (IDH) del año 1990, la isla se ubicaba en el puesto 37 entre 130 países. Sin embargo, en el año 1994 los altos niveles de precariedad económica como consecuencia del derrumbe del campo socialista la hicieron descender al puesto 89 de 173 países. A fines de la década de los noventa se observa una paulatina recuperación, que colocó nuevamente a la isla entre los 50 primeros puestos en el año 2000, con un índice de 0.742 (PNUD, 2000). 
Al tiempo que mejoraba su situación económica se podía observar también un ascenso dentro de la comunidad de países con un mayor índice de desarrollo humano. Para el año 2005 se ubica en el puesto 44, con un índice de 0.786. En el 2013 se registró su mayor crecimiento, con un índice de 0.815 (PNUD, 2013). Aún con la paulatina recuperación de Cuba en los últimos años, la isla no ha logrado volver al puesto 32 que ostentaba antes de iniciarse el Período Especial.

\subsection{Influencias de las teorías de desarrollo local en la Cuba revolucionaria}

Aunque desde el año 1959 Cuba ha llevado a cabo medidas proteccionistas en correspondencia con la pervivencia de su sistema económico y político, no escapó de la influencia que ejercieron las emergentes teorías de desarrollo desde la perspectiva local.

A fines de la década de los '80, en la isla se comienza a estudiar a los teóricos extranjeros del desarrollo local y sus presupuestos ideológicos. Esos planteamientos teórico-prácticos comienzan a ser contrastados con las realidades y los presupuestos teórico-ideológicos del sistema cubano. Al respecto, se inicia el estudio que introduce pequeñas modificaciones de los principios y los condicionamientos generales que permitieran la compatibilizar de las teorías de desarrollo local con el modelo y las estructuras políticas del gobierno revolucionario.

La vía maestra de inserción de esos nuevos argumentos teóricos fue precisamente la necesidad de darle un orden lógico y consciente al desarrollo de las localidades, el que hasta la fecha había sido trazado de forma empírica, como una simple respuesta del gobierno central a las demandas locales a través del Instituto de Planificación Física (IPF).

En el debate que se genera en la isla a partir de los '90 [recuérdese que hablamos del llamado Período Especial, tras el derrumbe de la URSS] y hasta la actualidad, emergen diversas dimensiones del desarrollo desde lo local, que son a su vez los puntos de partida de los estudios oficialistas. Desde esta óptica, se manejan distintos conceptos de lo que se entiende como desarrollo local. Entre ellos predominan aquellos que consideran que el desarrollo local es:

$\checkmark \quad$ Un proceso de aprendizaje donde la historia, el espacio y el tiempo determinan las acciones que llevan a cabo los actores políticos, económicos y sociales. Ese proceso que va unido a un conjunto de capacidades locales como la innovación, el desarrollo técnico, la capacidad emprendedora de los agentes sobre el terreno, la creatividad, la gestión de los recursos humanos, las dotes organizativas, la integración en el entorno estatal e institucional, junto a las leyes del mercado, la de liderazgo y la de capacidad de intercambio (Madoery, 2008).

$\checkmark \quad$ Un nuevo modo de actuación política que facilita el nacimiento de localidades más sostenibles, autosuficientes para satisfacer sus necesidades más básicas, explotar sus potencialidades endógenas y maximizar las ventajas comparativas locales para el comercio (Franco, 1998).

$\checkmark \quad$ Un proceso de concertación entre actores sociales cuya finalidad sea catalizar un proyecto común que logre incluir el desarrollo económico, la equidad, la cultura, la sustentabilidad, la diversidad de género, el cambio social, y que potencie el equilibrio 
territorial con el fin de elevar la calidad de vida en el territorio ${ }^{4}$ (Programa Delnet, 2002).

$\checkmark \quad$ La valorización del patrimonio cultural, las costumbres, tradiciones, saberes y modos de actuación innovadora, a través de dimensiones sostenibles que posibiliten el reforzamiento de la identidad local y su valor social.

Todo ello al menos en teoría, pues no fue sino hasta después de la desintegración de la Unión Soviética que el Estado se vio obligado a redirigir su mirada a la dinamización de las potencialidades endógenas de cada uno de los territorios del país. Se trataba de mitigar en lo posible los efectos de la crisis económica.

A partir de la década de los noventa se asiste a un verdadero y creciente interés por el tema del desarrollo local. Los conceptos de desarrollo territorial, desarrollo sustentable y desarrollo humano, serán incorporados de manera consciente, y su uso será cada vez máscomún en cada una de las estrategias político-territoriales que se implementarán.

Aún con la tardía incorporación de Cuba a las líneas temáticas y teórico-prácticas del desarrollo local, los avances debieran haber sido, cualitativa y cuantitativamente, superiores a los conseguidos en la actualidad. Si establecemos un estudio comparativo con otras realidades (como la europea), encontraremos que es aún muy limitado el conocimiento que -entre sociólogos, geógrafos, historiadores y economistas cubanos- se ha acumulado respecto de las teorías de desarrollo local. Eso, además del escaso registro de casos reales en los que se hayan explotado las potencialidades de los territorios en función de las necesidades locales.

Al respecto, Hernández (2005) considera que todo ello ha respondido a que los estudios se enfocan hacia la promoción del desarrollo local como alternativa a la crisis económica que se inició en los '90 y no como una solución definitiva a los problemas del desarrollo de los territorios en todas sus dimensiones ${ }^{5}$.

En la parte positiva del balance a resaltar como fruto de las influencias que ha ejercido la teorización del desarrollo local en Cuba, podemos destacar que el discurso sobre lo local se ha logrado incorporar al marco académico-investigativo. Se ha entronizado en el debate la necesidad de su replanteamiento desde la actualidad política y económica del país, y en este sentido se incorporó la historia local como un elemento fundamental a tener en cuenta en las políticas de desarrollo; se entendió que es imposible establecer buenas prácticas en políticas de desarrollo local sin antes tener en cuenta las delimitaciones físicas no solo desde el punto de vista geográfico sino también histórico,

\footnotetext{
4 “Durante la década del 90, paralelo al proceso de renovación del discurso sobre desarrollo humano en el ámbito internacional, en el movimiento feminista se fue consolidando la reflexión sobre la relación entre equidad de género y desarrollo humano, así como se fue trabajando en el área del impulso a políticas nacionales y locales que transitaran de los enfoques de mujer en el desarrollo al de género en el desarrollo" (Fleitas, PNUD Cuba, 2005: XIII).

${ }^{5}$ La descentralización de poder, el uso del espacio físico, la gestión económica y el valor de la iniciativa comunitaria son algunas de las aristas discursivas que cada vez encuentran espacios mayores dentro de talleres, conferencias y publicaciones sobre el tema. PNUD Cuba (2005: 189) considera que esta perspectiva de análisis no se limita al espacio físico, incluye las actividades económicas, que tienen que ver con los recursos naturales de los territorios (Labrada, 2008).
} 
junto a las características culturales, socio-económicas y sus nexos con el gobierno provincial y nacional ${ }^{6}$.

La premisa gubernamental durante estos años -al menos en el ámbito de la teoría- estuvo condicionada por la estrecha relación entre la base económica y sus repercusiones en la vida social, lo que motivó impulsar políticas de tratamiento simultáneo de los problemas económicos y sociales. Este tipo de enfoque se convirtió en una de las características predominantes del modelo de desarrollo esbozado previamente por Carlos Rafael Rodríguez ${ }^{7}$ desde el año 1983. Ese modelo se sustentaba en una clara concepción teórica acerca de la naturaleza multidimensional del fenómeno del desarrollo, con la certeza de que la simultaneidad permitiría liberar las fuerzas sinérgicas que el proceso mismo desataría (Hernández, 2004).

El complejo proceso de transformaciones revolucionarias se basó, especialmente desde los '90, en esa concepción integral del desarrollo. Hay que decir, no obstante, que desde los años '60, las leyes revolucionarias de nacionalización y creación de la propiedad del Estado, de industrialización y desarrollo de la agricultura, de solución a los problemas cruciales y acceso universal a la educación, la salud y la cultura habían promovido el desarrollo humano.

Pese a tan temprana concepción, es cierto -como sostienen Hernández (1998) y Machado (2004)- que no es hasta 1968 que en Cuba se genera un primer proyecto integral de desarrollo ${ }^{8}$, pero debemos tener muy en cuenta la propia complejidad de la construcción socialista, así como las dificultades que en el escenario internacional enfrentaba. Más allá de una exhaustiva elaboración teórica, las políticas de desarrollo estaban respondiendo desde el propio triunfo de la Revolución a una visión integral, según la cual las tareas de consolidación del poder gubernamental, el fortalecimiento de la independencia nacional, los cambios estructurales en la economía, el desarrollo agropecuario y la industrialización eran temas prioritarios junto a la formación educacional permanente y creciente de la población.

Es por ello que la concepción que implementará posteriormente el PNUD resulta familiar y es finalmente incorporada de forma teórica al escenario académico cubano y en el escenario de los actores políticos, ya que sustentan las acciones sobre el desarrollo relacionadas sobre todo con las capacidades humanas, la seguridad social, educacional y de salud que en la isla se habían implementado desde treinta años atrás como parte del proyecto social revolucionario. Luego, más tarde, se sabría cuan de dependiente del subsidio soviético serían estos logros.

Ajenos a esta realidad que ahora podemos certificar, estudios iniciados desde 1996 en Cuba ${ }^{9}$, conciben el desarrollo humano no sólo como crecimiento económico, sino que incluye la formación de capacidades humanas y el uso que la gente hace de ellas. Con dimensiones como la equidad, la

\footnotetext{
${ }^{6}$ Vid., Guzón, A. (2004. "Los municipios y sus potencialidades para el desarrollo local” en CIPS. Boletín electrónico. Año 1 no.3 nov. 2004, La Habana.

${ }^{7}$ Importante político, economista y comunista cubano (1913-1997).

${ }^{8}$ Este autor ubica el proyecto en la zafra de 1970, de cuyos resultados se derivaría un salto en el desarrollo, puesto que “(...) la primera década de la revolución fue de resistencia, de consolidación del poder, de aprender avivir bloqueados económicamente y andar los primeros pasos en un aprendizaje de administración socialista" (Machado, 2004).

${ }^{9}$ Vid., CIEM (1997.Investigación sobre el desarrollo humano en Cuba, La Habana, Caguayo SA y CIEM (2000.Investigación sobre el desarrollo humano y equidad en Cuba. 1999.
} 
sustentabilidad, la productividad, la potenciación, la cooperación y la seguridad ${ }^{10}$ (Labrada, 2008).

\subsection{El proceso evolutivo de los organismos de control del Estado vinculados al desarrollo local.}

Para comprender cuáles fueron los objetivos e intereses del gobierno revolucionario es necesario hacer un recorrido evolutivo sobre los organismos de control administrativo del Estado a partir del año 1959 y hasta la actualidad. Es el período en el que se comienza a experimentar para encontrar las instituciones definitivas, favorecedoras del desarrollo y que estuvieran en correspondencia con la nueva sociedad en construcción. Una etapa en la que se consideró que lo viejo debía ser sustituido por lo nuevo y era necesaria, por tanto, una nueva estructura local que rompiera con toda la maquinaria y las estructuras capitalistas precedentes.

Las primeras estructuras del poder local creadas por la Revolución transitaron por diversos nombres y facultades. Se comenzó por la Institución del Comisionado, luego la Junta de Coordinación, Ejecución e Inspección (JUCEI), las Administraciones Locales (en su momento conocidas como Poder Local) y los Órganos Locales de Poder Popular. Esta última, el Poder Popular, ha resultado la forma definitiva.

La Institución del Comisionado (Ley 36/1959), sustituyó a los antiguos gobernadores provinciales, designados por el Ministro de Gobernación. Ésta se componía de tres comisionados, quienes a su vez poseían facultades limitadas para dirigir los municipios. Son los comisionados los llamados a sustituir a los Alcaldes y Concejales municipales.

Si bien esta Institución inició una nueva etapa (1959 y 1961) -para algunos cualitativamente superior- evidenció también sus limitaciones para la materialización de los ideales revolucionarios en cuanto a la participación del pueblo en el marco local. Aunque, por otra parte, expresaban un poder altamente centralizado en tanto los comisionados eran atendidos directamente por el Ministro de Gobernación.

En su sustitución fue creada una nueva estructura local de gobierno, laJUCEI(1961 - 1966), que poseía un mayor grado de integración y participación. En ella interactuaban representantes de las organizaciones políticas y de masas de las Delegaciones de los Organismos Administrativos del Estado en el territorio ${ }^{11}$. Como resultado de la existencia de las JUCEI, pudo determinarse las limitaciones precedentes para asegurar [supuestamente] el ejercicio del poder por parte de las masas populares (Tejera, 2007).

Esta institución se desempeñó, como gobierno local en los territorios municipales al igual que en las regiones y provincias- coordinando toda la actividad política y administrativa aunque, de hecho, siempre subordinada al gobierno central. Para garantizar la dirección de las JUCEI se creó la Coordinación Nacional, encargada de su

\footnotetext{
10 Vid., Márquez, Miguel (2004. El desarrollo humano desde una perspectiva integral y su proyección mundial. En Desarrollo Humano Local, La Habana, Universidad de La Habana.

${ }^{11}$ Según Domingo García Cárdenas, con estas estructuras "Ia instancia provincial vio incrementadas sus atribuciones respecto a los municipios". Vea, Domingo García Cárdenas. "La organización estatal en Cuba”, Universidad de Oriente, Serie DerechoNo. 4, Santiago de Cuba, 1982, p. 12.
} 
orientación y control.

Las Administraciones Locales (1966-1976) por su parte, fueron la institución que mejor reflejó los principios de la dirección política de la Revolución en las estructuras de gobierno local. No obstante, debemos apuntar que también es éste el período de mayor control y centralización de la historia reciente de Cuba, en el cual se agudizaron las diferencias socioeconómicas entre las distintas provincias del país. Los presidentes de éstas Administraciones en los municipios eran elegidos en asambleas plenarias de los militantes del Partido Comunista del territorio. Ésta fórmula de gobierno local se mantuvo hasta la instauración del Poder Popular, después del Primer Congreso del Partido Comunista de Cuba, en 1975.

En los municipios, las Administraciones Localesestaban integradas por un Comité Ejecutivo, en el cual participaban también las Direcciones de las organizaciones de masas y, además, diez delegados elegidos por la población en Asambleas efectuadas en centros de trabajo y barrios. Los delegados electos integraban las comisiones de trabajo, y seleccionaban al personal auxiliar para la administración de las diferentes actividades a su cargo.

Posteriormente,los Órganos Representativos del Poder (Asamblea del Poder Popular (1975), permitieron que la Asamblea Municipal y su Comité Ejecutivo organizaran la vida política administrativa de los territorios, según lo preceptuado en la Constitución de 1976 (capítulo IX, art. 102, 103).

Desde la década del '60, el gobierno había decidido incrementar el número de municipios y fortalecer el papel y la autoridad de las instancias provinciales de gobierno. Se había creado una estructura intermedia, entre la provincia y el Estado, llamada Región, con el objetivo de mejorar el sistema organizativo y la dirección territorial de las actividades económicas y sociales. Sin embargo en 1975 (como resultado de la entrada en vigor de la nueva Constitución) se decidió adoptar una nueva División PolíticoAdministrativa (DPA), mediante la cual se suprimiera el eslabón regional y aumentara el número de provincias de seis a catorce, al tiempo que disminuía el de municipios de 407 a 169, incluido el municipio especial Isla de Pinos (Ilamado desde 1978, Isla de la Juventud) ${ }^{12}$.

Ésta DPA facilitó el desarrollo socioeconómico según afirman algunos estudiosos. Es un período de búsqueda de nuevas estructuras de gobiernos locales, en correspondencia con las necesidades de la evolución política y social durante el proceso de construcción del nuevo sistema instaurado ${ }^{13}$.

A ésta nueva estructura se añadieron, diez años más tarde en el III Congreso del PCC (1986), los distritos (con carácter excepcional) y los Consejos Populares, pero no significó en modo alguno la descentralización de los poderes del Estado. Se acordó el reordenamiento de la división política

\footnotetext{
${ }^{12}$ Concluida la Guerra de los Diez Años, el régimen colonial introdujo algunas reformas, incluida una nueva división a tenor con la cual se descentralizaba en cierta medida la gobernación del país. A tal efecto, un Real Decreto del 9 de junio de 1878 creaba seis provincias que tomarían los nombres de sus respectivas capitales: Pinar del Río, La Habana, Matanzas, Santa Clara, Puerto Príncipe y Santiago de Cuba; y ésta a su vez quedaban divididas en término municipales. (Tomado de Ecured.cu)

${ }^{13}$ Se refiere a la creación de centros de estudio de desarrollo local adscritos a universidades y a los gobiernos locales, al CITMA entre otros.
} 
administrativa, así como la introducción de enmiendas complementarias para fortalecer el gobierno provincial en cada localidad a través de los citados Consejos Populares ${ }^{14}$. En ellos se pretendía sintetizar la dirección colectiva, la integración de las organizaciones sociales y de masas, las entidades administrativas de cualquier subordinación y la acción participativa de la población, con lo cual se pretendía elevar el trabajo del poder popular a nuevos niveles (Rodríguez, 2004). Entendemos, más bien, que se trató del nacimiento de un nuevo órgano de control estatal centralizado cuyos objetivos son diversos y en ocasiones difusos.

Estamos, por tanto, ante una realidad administrativa que corresponde a un modelo de desarrollo centralizado ${ }^{15}$ que deja poco margen para acciones de auto-transformación local. Aquella que, con la durísima crisis y la Reformade los años 90, hizo evidente tanto la relevancia de los ámbitos locales y comunitarios como las desventajas y las desigualdades entre ellos a la hora de la aplicación de las decisiones estratégicas (Espina, 2006).

Para comprender a qué respondió el viraje en la política económica que rigió hasta 1992, debemos retroceder un año. En 1991 concluyó el proceso de desintegración del socialismo en Europa del Este con la desaparición de la Unión Soviética; muchos en todo el mundo se cuestionaron la posibilidad de que Cuba pudiera continuar con el socialismo, y más aún, que fuera capaz de sobrevivir al tsunami económico que significó el hundimiento del ícono mundial del comunismo.

Los efectos en la sociedad cubana fueron devastadores. Hasta la fecha se había alcanzado un exagerado nivel de dependencia, adquirido desde los primeros años del triunfo de la Revolución, del intercambio comercial con los países del conjunto de Europa del Este a través del Consejo de Ayuda Mutua (CAME). Ante el hundimiento de las relaciones económicas y políticas de la isla con los países del desaparecido bloque socialista, Cuba entró inevitablemente en lo que se conoce como Período Especial. (Vea tabla 1.1. Algunas de las consecuencias económicas que afrontó Cuba al desaparecer el CAME)

Ante dicha situación, el Régimen dijo no querer acudir a los métodos típicos del Fondo Monetario Internacional (FMI) y el Banco Mundial (BM), pues su empleo devendría en "la destrucción

\footnotetext{
${ }^{14}$ Mediante la ley \# 56, de 4 de julio de 1986, se modificaron las Normas Reglamentarias de las Asambleas Municipales y se facultó a estas para crear los Consejos Populares "en núcleos de población que no constituyeran cabeceras de municipio y contaran con una apreciable cantidad de habitantes y significativo volumen de actividad productiva y de servicios". En julio de 1988 se creó el primer Consejo Popular en San Antonio de las Vegas, La Habana. De 1988 a 1990 se crearon 225 en todo el país. Así concluye la primera etapa de su implantación. En octubre de 1990 se comienza su implementación en Ciudad de La Habana, mediante Acuerdo del Consejo de Estado, relativo a los Consejos Populares. Se inicia una segunda etapa, como parte de la cual en 1991 se decide extenderlos a todo el país, "atendiendo a las características y peculiaridades de cada lugar". La Reforma Constitucional de 1992 refrenda los Consejos Populares, al tiempo que reconoce al Distrito como parte de la división político administrativa. El 10 de enero de 1993, por acuerdo 2654 del Comité Ejecutivo del Consejo de Ministros (CECM) se liberan las Normas referentes a la Organización, Integración y Atribuciones de las Administraciones Municipales, subordinadas a las respectivas Asambleas. Los Comités Ejecutivos pasaron a la historia. Posteriormente, en 1995 se aprueban los Reglamentos de las Asambleas Municipales. En julio del 2000, en las sesiones del 12 y 13, la Asamblea nacional del Poder Popular, aprobó la Ley que regula la organización y funcionamiento de los Consejos Populares, iniciándose una tercera etapa en su desarrollo (Tejera, 2007).

${ }^{15}$ Vid., Ada Guzón Camporredondo (compiladora.El desarrollo local en Cuba. Retos y perspectivas. Editorial Academia, La Habana, 2006.
} 
del consenso político alcanzado" [sic] y agravaría la crisis económica que, a su vez, desencadenaría una crisis ideológica y social en la isla. Esa política trajo como consecuencia la implementación de reformas que entrañaban serias afectaciones a las relaciones sociales hasta ese momento vigentes en el país (Labrada, 2008).

Tabla 1.1. Algunas de las consecuencias económicas que afrontó Cuba al desaparecer el CAME.

CONSECUENCIAS ECONÓMICAS PARA CUBA TRAS LA DESAPARICIÓN DEL SOCIALISMO EN EUROPA

\begin{tabular}{|c|c|}
\hline $\begin{array}{c}\text { 1992, el intercambio comercial con } \\
\text { respecto a } 1989 \text { había disminuido en un 70\%. }\end{array}$ & $\begin{array}{c}\text { El consumo de calorías, por parte de la } \\
\text { población, se redujo de } 3000 \text { (1989) a } 1863 \\
(1993) .\end{array}$ \\
\hline $\begin{array}{c}\text { El PIB decreció en un 24\%, y el uso de } \\
\text { la capacidad industrial instalada en un 30\%. }\end{array}$ & $\begin{array}{c}\text { El consumo de proteínas diarias se } \\
\text { redujo de 75g (1989) a 46g (1993). }\end{array}$ \\
\hline $\begin{array}{c}\text { El déficit presupuestario aumentó en } \\
1993 \text { a } 5000 \text { millones de pesos. }\end{array}$ & $\begin{array}{l}\text { La construcción de viviendas disminuyó } \\
\text { de 39589 en 1989 a 20 030 en 1993. }\end{array}$ \\
\hline
\end{tabular}

Fuente: Cantón y Silva (2009).

Ante el panorama internacional de colapso de un sistema del que Cuba era un simple peón, se abrían diversas posibilidades de cambio o de transición a hacia nueva realidad que le permitiera sobrevivir económicamente y salvar a toda costa los principios de la Revolución, aunque algunos de ellos se perdieran en el camino. Entonces las preguntas fueron: ¿Transición hacia dónde? ¿Qué cambios, cómo?

Diversos analistas políticos internacionales apuntan que hubo un amplio abanico de opciones por las que el gobierno cubano pudo optar para su supervivencia económica, no así para la ideológica. Según Viciano (2000), las posibilidades reales podríamos situarlas en cuatro direcciones fundamentalmente. La primera opción era mantener el sistema político y económico, sin alteraciones. Frente a esta posibilidad -ciertamente la más simple en aquel contexto-, el gobierno corría el riesgo latente de hacer colapsar más temprano que tarde la débil economía del país. Por otro lado, optar por ésta vía, abriría una brecha para una posible insubordinación civil contra la inmovilidad del Estado para resolver la inevitable crisis económica que le había sobrevenido. Dicha violencia podría estar apoyada por los opositores al régimen, por los exiliados políticos y por el propio gobierno norteamericano. Todo lo cual tendría unas repercusiones internacionales de apoyo a la inserción de Cuba en el sistema y en el modelo de democracia occidental sin importar las consecuencias que ello tendría en la vida concreta de la población.

La segunda posibilidad consistía en el mantenimiento del status quo político y en la introducción de cambios económicospropios de un sistema de mercado. El ejemplo más cercano de su aplicación se ofrecía en países como China y Vietnam. Ésta fórmula podía asegurar el mantenimiento de las estructuras de poder por un tiempo, siempre que el Estado supiese hacer un buen uso de los poderes públicos en cuanto al manejo de sus medios. Pero la dificultad que presentaba ésta alternativa consistía en que con los 
cambios económicos, avalados por unos imprescindibles cambios de la normativa jurídica, harían aparecer a corto plazo nuevas formas de relaciones sociales. Las cuales estarían acompañadas -probablemente- por una importante reacción ciudadana contra el poder político en busca de cambios en su estructura (Viciano, 2000).

La tercera vía de escape era la transformación del sistema político y económico y su derivación hacia un sistema de producción capitalista, como había ocurrido con los países que habían formado parte del bloque soviético. Ésta era, quizá, la opción más deseada por parte de aquellos partidarios de la eliminación de todo vestigio comunista en el planeta, aunque "esa transformación absoluta conllevaba numerosas renuncias: no sólo a la creación de un Estado y una sociedad socialistas [inaceptable para la dirigencia histórica del proceso] sino además, entre los potenciales partidarios de los cambios, el convencimiento de que la pérdida del poder conllevaría a la represión por parte de los nuevos actores" (Viciano, 2000: 85).

Frente a éste panorama existía una cuarta alternativa, mucho más compleja, que demandaba de la movilización de recursos humanos, intelectuales y políticos más importante en la historia de la República. Se pensó en una transformación profunda, en una reforma del sistema económico y político hacia un nuevo modelo de socialismo. Una reforma que estuviera en sintonía con las circunstancias históricas concretas, pero que en modo alguno hicieran abandonar los principios y las conquistas fundamentales de la Revolución. Se trataba de una vía que había de ser tanto alternativa al sistema de relaciones político-económico y social neoliberal como alternativa al difunto sistema soviético.

En su momento, analistas occidentales consideraron que Cuba había optado por la tercera alternativa (paso al Estado capitalista), una teoría que surge a raíz de las reformas económicas que se sucedieron en la isla en la década de los 90 , y a la que nos referiremos más adelante. En cambio algunos analistas de la izquierda más próxima al Régimen afirmaron que la adoptada finalmente había sido la cuarta vía (conversión política y económica a un modelo novedoso).

Veinte años después, podemos decir que la opción que tomó Cuba se acercaba mucho más a la segunda alternativa que a ninguna otra (mantenimiento del status quo e introducción de cambios económicos propios de un sistema de mercado). Se optó por sobrevivir económicamente en un mundo unipolar (capitalista), introduciendo pequeñas dosis de cambios en el diseño y las estructuras políticas del país (Viciano, 2000).

Es por ello que el 10 de octubre de 1991, como parte de la respuesta estatal a la delicada situación, se llevó a cabo el IV Congreso del Partido Comunista de Cuba (PCC). En él se aprobó un grupo de resoluciones relacionadas con su vida interna, y se ratificó la reforma de tres pilares fundamentales de la nueva orientación política de régimen: el desarrollo económico, el perfeccionamiento de los Órganos del Poder Popular y la política exterior ${ }^{16}$.

Según Cantón y Silva (2009), en el orden económico la estrategia trazada para salir de la crisis estuvo dirigida a incrementar y potenciar el desarrollo del turismo, a fomentar el estímulo a la inversión extranjera en forma de empresas mixtas u otros métodos de asociación donde el Estado fuera el accionista mayoritario. También en la activación del trabajo por cuenta propia, así como a la despenalización de la tenencia y el empleo de la moneda libremente convertible (dólar). En paralelo

\footnotetext{
${ }^{16}$ Las reformas fueron implementadas a partir del año 1992.
} 
con ésta, se propició la apertura de tiendas y servicios, mediante los cuales las divisas pudiesen ser captadas por el Estado.

Se reorganizó el sistema empresarial con la creación de corporaciones que operaban en moneda libremente convertible. Se implementó un nuevo y riguroso sistema tributario. Se llevó a cabo una reforma del comercio exterior que incluyó la autorización a determinadas empresas cubanas a comerciar directamente con firmas extranjeras sin la mediación del Ministerio de Comercio Exterior.

En el orden político, las reformas realizadas respondían al supuesto perfeccionamiento de la democracia socialista que se sintetiza fundamentalmente en el más idóneo funcionamiento de los Órganos del Poder Popular, en el que se ratificaba al PCC como fuerza dirigente del Estado y de la sociedad. Se estableció un cambio conceptual en la Constitución de 1976, según el cual se le otorgó al Estado cubano una nueva denominación: pasaba de ser un Estado Ateo a ser un Estado Laico. Se establecieron las funciones del órgano administrativo y del legislativo (Asamblea Nacional), dotándola de nuevos instrumentos para el ejercicio de sus funciones. En consonancia y en relación con las administraciones locales, se concedió nuevamente personalidad jurídica a los municipios, pasando a ser reconocidos como órganos de dirección capaces de ejercer por si mismos sus derechos y asumir sus obligaciones ${ }^{17}$.

El objetivo de ésta medida fue crear las bases para la descentralización del aparato administrativo Estatal. La reforma también marcó -más allá de las administraciones locales y provinciales- el inicio de un largo proceso de análisis para el otorgamiento de autonomía a las empresas, y para el control sobre la gestión de sus recursos. Se trataba de un primer paso que se gestionaba sólo en el ámbito empresarial -con algunas limitaciones desde el punto de vista económico, pero que constituyó un importante punto de partida en el proceso de descentralización.

El enfoque de la reforma (político-económica) gubernamental respondía a la concepción del desarrollo del país y a la necesidad de que el Estado conservara su capacidad redistributiva y de control sobre la economía, así como que mantuviera la hegemonía de la propiedad y de los servicios públicos, aunque introducía cuotas de descentralización a favor de los decisores empresariales y los gobiernos locales, al ampliar los márgenes de funcionamiento del mercado y de los agentes económicos no estatales. Todo ello permitiría atenuar las desventajas particulares y atender a las situaciones extremas, así como estimular las opciones innovadoras en la medida de lo posible (Espina, 2006).

Dichos cambios proporcionaron la diversificación de la estructura administrativa a escala social y territorial, así como el continuo reforzamiento para la eliminación de los evidentes contrastes locales, los cuales escapaban y escapan de la posibilidad de manejos focalizados por parte de una entidad estatal central y demandan herramientas de desarrollo local.

\subsection{Parámetros económicos y políticos básicos de la Cuba actual que afectan al desarrollo Local.}

Desde el punto de vista teórico, especialistas en la temática como Albuquerque (2004) y Noguera (2015: 18-26), afirman que el fracaso de las políticas tradicionales de desarrollo (top-down) para dar respuesta a las problemáticas de las localidades, han conducido necesariamente a la aparición de nuevas políticas de desarrollo que comparten cuatro

\footnotetext{
${ }^{17}$ Decreto Ley 147 de la Reorganización de los Organismos de la Administración Central del Estado, abril de 1994.
} 
rasgos comunes: son específicas de cada territorio, requieren de la participación y de la concertación social, de la responsabilidad de su diseño y de la gestión de los agentes locales, e implican la movilización de los recursos locales y la activación de las ventajas comparativas del territorio. (Ver tabla 1.2. Diferencias entre el enfoque de "arriba a abajo" y el enfoque "de abajo a arriba" del desarrollo)

Aunque se reconoce el valor y la pertinencia del mantenimiento de las políticas (top-down), fundamentalmente para la acción pública en pos del desarrollo, se ha hecho necesaria la implementación de un modelo mucho más descentralizado que permitiera dar respuesta a las demandas locales, usando como base las potencialidades y deficiencias propias de cada territorio, a pesar de que ella (la política bottom-up) entraña en sí misma diversos retos y riesgos(Ver tabla 1.3. Retos y riesgos de la aplicación del modelo bottomup en las localidades).

Tabla 1.2. Diferencias entre el enfoque de "top-down" y el enfoque "bottomup" del desarrollo).
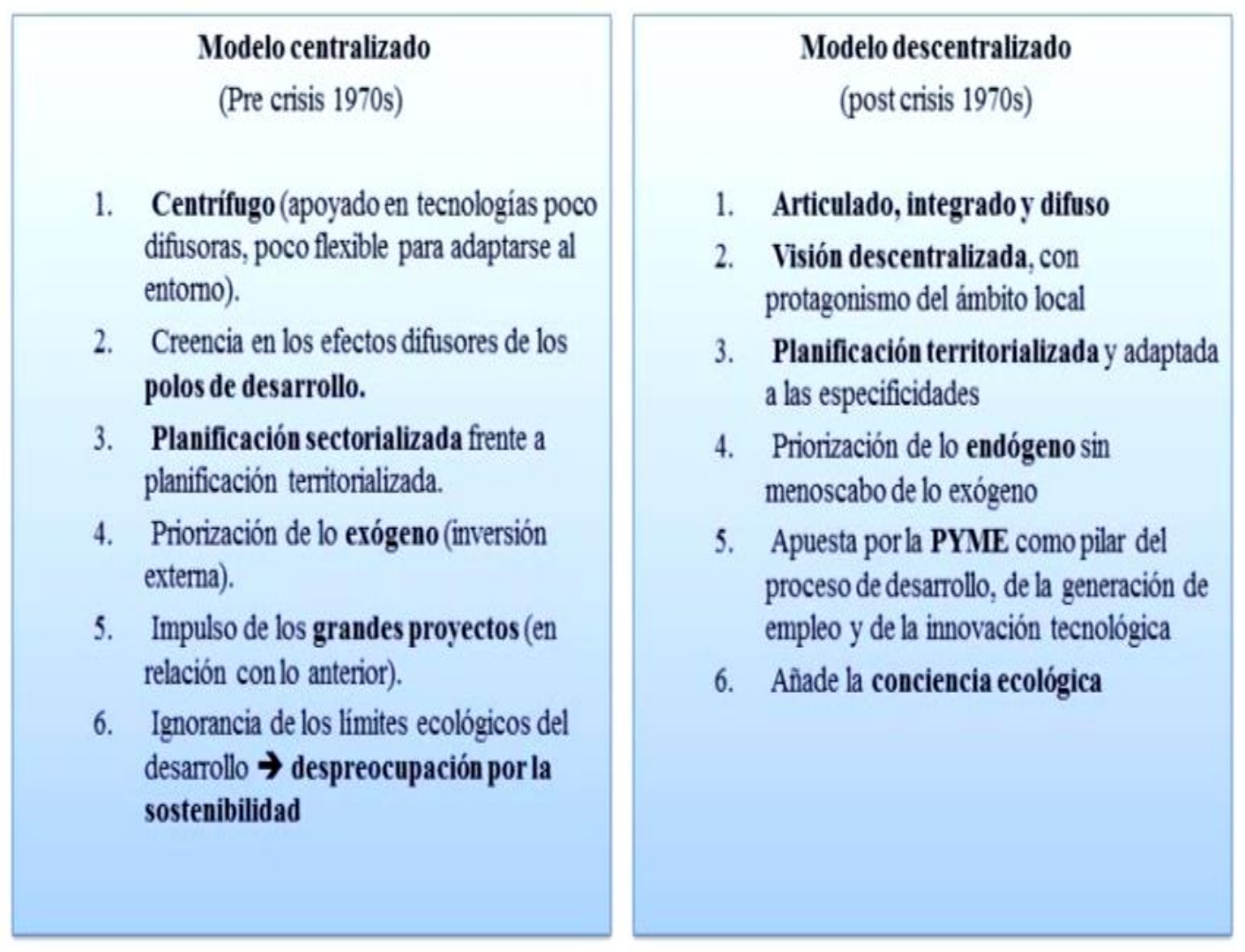

Fuente: Noguera (2015: 18). 
De forma general, los principales beneficios que se pueden percibir con la aplicación de políticas descentralizadas (bottom-up),giran en torno a un mayor empoderamiento de los agentes locales y de la sociedad en su conjunto, en consonancia con una mayor transparencia por parte de las instituciones del territorio. Desde esta concepción, se aspira a que las empresas sientan una mayor implicación con su localidad, en tanto que deben responder a las potencialidades de la misma, creando con ello su propio sello de identidad. Una implicación que debe redundar en un mayor grado de integración, de sostenibilidad económica y de generación de empleo como consecuencia de ello (Noguera, 2015).

A pesar de las evidentes ventajas, también se aprecian procesos complicados y retos ante la implementación de éste modelo descentralizado (bottom-up). Algunos de estos pueden, -como veremos más adelante- lejos de crear sinergias y sentido de pertenencia, provocar serios inconvenientes para la puesta en marcha de políticas y estrategias de desarrollo local que beneficien a la sociedad en su conjunto.

Tabla 1.3. Principales exigencias y riesgos en la aplicación del modelo (bottomup) en las localidades.

\begin{tabular}{|c|c|}
\hline EXIGENCIAS & RIESGOS \\
\hline $\begin{array}{l}\text { Una adecuada concertación social, y el } \\
\text { establecimiento de adecuados } \\
\text { mecanismos de coordinación entre las } \\
\text { instituciones. } \\
\text { Lograr una visión común del futuro } \\
\text { deseado y posible del territorio. } \\
\text { Mayores exigencias para lograr las } \\
\text { metas teniendo en cuenta la velocidad de } \\
\text { los cambios externos que inciden la toma } \\
\text { de decisiones. } \\
\text { Lograr una mayor sostenibilidad del } \\
\text { modelo económico social. } \\
\text { Lograr el empoderamiento real de } \\
\text { todos los actores locales. }\end{array}$ & $\begin{array}{l}\text { No hay garantía de éxito. Aun cuando se } \\
\text { haya establecido una adecuada concertación } \\
\text { y una adecuada gestión del proceso. } \\
\text { No ser capaces de identificar, diseñar e } \\
\text { implementar una adecuada estrategia de } \\
\text { desarrollo para el territorio. } \\
\text { Prioridad a políticas de desarrollo } \\
\text { territorial a corto plazo. } \\
\text { Decantación y perversión del modelo a } \\
\text { través de estrategias que beneficien a } \\
\text { determinados intereses. Dígase grandes } \\
\text { intereses privados no potenciadores del } \\
\text { beneficio común, y dígase estrategias de un } \\
\text { marcado populismo por parte de una élite } \\
\text { política. }\end{array}$ \\
\hline
\end{tabular}

Fuente: Elaboración propia, datos tomados de Noguera (2015). 
Pike etal. (2011: 176-183) argumentan que en la actualidad el mundo "se mueve de una era de gobierno a una de gobernanza", en la que la descentralización Estatal transita hacia un "nuevo regionalismo" o a un nuevo "localismo". Una era en la que la gestión pública es multinivel y abarca una amplia gama de estratos que van de lo supranacional hasta la comunidad local. Este proceso adquiere mucho más valor si se tiene en cuenta que la actuación del Estado, sea cual sea, tiene consecuencias importantes sobre el territorio.

En dicho tránsito, de gobierno a gobernanza, se evidencian al menos tres grandes cambios:

a) El papel del Estado, y todo su aparato oficial en la gestión de las políticas de desarrollo y los proyectos económicos ha decrecido en comparación con su influencia dos décadas atrás. En su lugar se propició la creación de partenariados entre organizaciones no gubernamentales y gubernamentales ${ }^{18}$.

b) Se asiste a un vaciamiento del Estado a través del reordenamiento territorial. Esto significa que las funciones del Estado se diseminan hacia arriba, en beneficio de instituciones supranacionales, como por ejemplo: el FMI, MERCOSUR, la Unión Europea, entre otros. Vivimos una coyuntura en la que el contexto internacional incide cada vez más en las decisiones políticas internas de los Estados, eso por no hablar de la cesión de soberanía que implica, por ejemplo, la pertenencia a la Unión Europea.

c) La capacidad y las atribuciones de los Estados se ven drásticamente afectadas por las regulaciones de dichos organismos internacionales. Los cuales cada vez más se ocupan, e interfieren, no sólo en los asuntos de orden internacional sino también -como hemos dicho-en los asuntos internos de sus países miembros.

Debemos destacar que incluso entre los defensores de ese tránsito hay un reconocimiento -como confirma Noguera (2015)-, de que éste entraña diversas problemáticas, como por ejemplo los antagonismos que se pueden generar entre actores e instituciones en la toma de decisiones, que pugnan por detentar parcelas de poder que antes ejercía el Estado. Es por ello que una de las premisas para el buen desempeño de la gobernanza lo constituye el reconocimiento, por parte de todos los actores, de la importancia relevante del gobierno nacional (Pike et allí, 2011).

El objetivo primero de ésta transformación del Estado es el de establecer mecanismos de gobierno que no se basen en el recurso de la capacidad autoritaria y sancionadora de éste, sino en la interacción entre múltiples actores, entre los que deben existir altas dosis de confianza para su real eficacia y eficiencia (Pike et allí, 2011).

Teniendo en cuenta todo lo dicho, se impone entonces un modelo territorial en el

${ }^{18}$ Vid., Pike et allí (2011.Desarrollo local y regional, p. 176. 
que prime una visión común acerca del futuro deseado, que sea sostenible y que permita el funcionamiento sinérgico de todos los actores políticos, económicos y sociales del territorio. Ello no debe significar que se transite de un Estado centralizado y autoritario a un Estado en el que la descentralización menoscabe su autoridad, vaya en detrimento de los intereses públicos y en favor de los grandes intereses económicos privados.

Tomando como base teórica lo expuesto acerca del papel del Estado en el diseño de las políticas económicas de desarrollo nacional, regional y local, podemos afirmar que Cuba conserva aún el estatus de Estado centralizado con una férrea política (top-down). El Estado revolucionario mantiene intacto el control sobre la dirección económica y jurídica de la isla aunque, como hemos señalado antes, otorgó pequeñas dosis de descentralización en favor del gobierno de los municipios y de algunos organismos a partir de la Reforma de 1992.

En este contexto, no se aprecia un cambio de gobierno a gobernanza, no existe una participación real de instituciones en el proceso (entre otras razones, por su débil institucionalidad), ni se aprecia la creación de partenariados. Se trata de un modelo que carece de integración con los diversos actores potenciadores del desarrollo, con una visión centralizada y poco flexible. Un sistema en el que prevalece la planificación sectorializada frente a la planificación del territorio, y en el que los recursos endógenos responden a una política económica de desarrollo nacional en detrimento de las localidades.

Es por ello que la comprensión de la relación entre el gobierno municipal y el desarrollo local en Cuba posee unos matices singulares cuando lo comparamos con otras experiencias. Una compresión que puede resultar todavía más compleja si tenemos en cuenta todos los factores que han incidido de forma negativa o positiva en la relación de éstos con el desarrollo de los territorios.

El primero de ellos, el Embargo Económico impuesto por el gobierno de los Estados Unidos desde el año 1961, ha dificultado considerablemente la implementación de buenas prácticas económicas y sociales, al tiempo que obligó a dejar inconclusos diversos proyectos de beneficio popular. No obstante debemos aclarar que ésta dificultad ha sido utilizada por el régimen para justificar -reiteradamente, por décadas-, la percepción de estancamiento económico que ha sufrido el país a ojos de sus habitantes.

Otro elemento a tener en cuenta, y que puede resultar de mucha importancia en el análisis que se propone, es la idea esbozada por Rafael Hernández cuando se refiere a la "mentalidad de fortaleza sitiada" ${ }^{19}$ de la sociedad cubana en las últimas décadas (Tejera, 2007). Esa mentalidad es un mecanismo de autodefensa contra lo externo, puesto que todos son considerados como potenciales enemigos de la Revolución y favorecedores de los intereses imperialistas [léase los Estados Unidos de América]. Desde esa lógica, el gobierno revolucionario fundó sus principios de supervivencia, no sólo en relación con su política exterior sino también con su lógica de funcionamiento interno.

Para nuestra sorpresa, existen muy pocas investigaciones que hagan un balance crítico y explícito de la relación real que existe entre el gobierno municipal y el desarrollo local. Cuando aludimos a la sorpresa nos referimos a que sin un previo balance autocrítico

\footnotetext{
19 Vid., Hernández, R. (1998. “¿Hacia una nueva sociedad socialista? Cambios, crisis y configuraciones sociales en Cuba", pp. 137-153.
} 
de las deficiencias en el manejo de las políticas de desarrollo local, resulta poco creíble que el gobierno manifieste su consciencia y su voluntad política para implementar los cambios necesarios.

Pese a lo que decimos, algunos autores relativamente críticos como Caballero y García (2004:118-119) han hecho un intento que se aproxima la elaboración de indicadores que permiten medir cualitativamente la relación que existe entre el gobierno municipal y el desarrollo local en la isla:

a) Nivel de participación de la población en la elaboración directa o indirecta de la política gubernamental.

b) Nivel de compromiso y participación en el proceso electoral.

c) Nivel de comunicación entre gobernantes y gobernados.

d) Niveles de calidad y efectividad en el ejercicio de las rendiciones de cuenta de los gobernantes ante los gobernados (representantes ante los representados).

e) Observancia del principio de revocabilidad de los gobernantes por los gobernados.

f) Promoción de procesos reales de participación en todas las dimensiones de la vida de la localidad.

g) Articulación sistémica, en la que se establecen contradicciones antagónicas entre los órganos de gobierno, las organizaciones políticas y sociales, así como las entidades e instituciones que confluyen en el territorio en función del desarrollo local.

Como podemos observar, éstos indicadores hacen énfasis sobre todo en la participación de la población en el diseño de políticas y en las decisiones del gobierno, además de tener como punto esencial la sinergia entre los actores involucrados en el proceso. Basándonos solamente en éstos indicadores, sin entrar aún en sus insuficiencias para medir la funcionalidad del gobierno municipal con el desarrollo local, podemos concluir que si aplicáramos cada uno de éstos, obtendríamos seguramente resultados negativos en todos los órdenes.

La causa fundamental se debe a que las estructuras del Estado cubano son altamente centralizadas, y a que los canales de comunicación e interacción entre la población y el gobierno municipal son insuficientes e ineficientes, por cuanto constituyen una mera imagen de representatividad que carece de una base jurídica que permita dar voz y visibilidad a las demandas de la población. Las estructuras vigentes son las que impiden la participación de la ciudadanía en el diseño de políticas de desarrollo local.

Si tenemos en consideración los principios básicos, la forma en que se establece la interacción entre el gobierno municipal y el resto de las estructuras del Estado, junto a los diversos actores locales que pueden y deben incidir en el diseño y aplicación de las políticas de desarrollo local, nos encontraremos ante una contradicción entre las estructuras, aparentemente diseñadas para propiciar la participación y la actuación de sus actores en pos del beneficio común, frente a su verdadero alcance. Por lo tanto, es fácil concluir que se requiere la introducción de cambios estructurales y jurídicos que permitan 
al gobierno municipal responder a las demandas del territorio y garantizar un resultado efectivo.

Por otra parte, entre los indicadores citados no se contemplan las iniciativas locales, ni aquellos aspectos culturales y de identidad local como elemento a tener en cuenta. Tampoco aparece como indicador la sostenibilidad del modelo, una dimensión determinante en el éxito o fracaso de las políticas de desarrollo en el territorio. Éstos indicadores, en nuestra opinión, carecen de integralidad en el análisis que nos ocupa.

Conscientes de lo complicado del tema y para hacer más comprensible la relación entre el gobierno municipal y el desarrollo local en la isla, consideramos necesario señalar los criterios teórico-metodológicos planteados por Guzón (2004) y Tejera (2007: 67-85) para medir dicha relación. Criterios que son, en realidad, las deficiencias y los obstáculos actuales entre el gobierno municipal y su territorio. Nos referimos a:

1. La evaluación de la calidad en el cumplimiento de las funciones gubernamentales.

2. La expresión de la calidad de la participación política en los asuntos locales.

3. La integralidad manifiesta en las diversas dimensiones en que se expresa el desarrollo local.

4. Las formas a través de las cuáles se consolida la identidad local, las formas de percibir lo local y el ambiente favorable a la transformación desde y para la sociedad local.

5. La calidad de la autonomía, entendida como creatividad, espíritu emprendedor, originalidad, utilización efectiva de la cultura local en función del desarrollo local.

6. La normatividad jurídica.

7. La sostenibilidad ambiental.

Estos indicadores facilitan una compresión más precisa en la delimitación de las dificultades que obstaculizan el trabajo del gobierno local en el desarrollo del territorio. Aunque en las fuentes consultadas no se aprecia un balance crítico real de la situación que atraviesan los municipios y sus actores, para la puesta en marcha de propuestas de desarrollo en sus territorios. El obstáculo finalmente insalvable es que la dirección política está absolutamente centralizada y todo cuanto se salga de ella puede ser objeto de disfunciones múltiples.

Cuando se habla, por ejemplo, de la evaluación de la calidad en el cumplimiento de las funciones del gobierno municipal (eficacia y eficiencia), se refiere al cumplimiento del rol que ha sido adjudicado al gobierno municipal y de la competencia estructural y práctica en su desempeño. Es decir, si realmente cuenta con la autonomía, la legalidad y los recursos para actuar a favor del desarrollo local (Tejera, 2007). Así mismo, se debe tener en cuenta que para el cumplimiento de las funciones gubernamentales locales respecto al desarrollo social se exige disponer de la competencia política y jurídica necesaria.

Por otra parte, la competencia de los órganos locales va estrechamente vinculada a estatutos y a normas políticas que definen la forma y el alcance de las estructuras y de sus 
actores políticos. Competencias que, en el caso de Cuba, no han sido ni son suficientes aún después de la Reforma de 1992. Las causas de ese subdesarrollo político y de la ineficiencia en la potenciación del desarrollo local por parte de los gobiernos municipales, se explican desde la historia, aspecto al que ya hemos hecho referencia.

Acerca de la participación, se afirma que sólo a través del ejercicio de ésta puede lograrse un continuo y ascendente crecimiento de la cultura política, de la incorporación de valores cívicos apropiados, del afianzamiento de la identidad local y con ello del crecimiento de la responsabilidad y del compromiso de la ciudadanía. Al respecto, cabe apuntar que en la isla existen importantes limitaciones a la participación política, asociadas no sólo a los estrechos espacios diseñados para ese fin, sino también a una insuficiente cultura política general.

En este sentido, consideramos que con una adecuada participación política de la ciudadanía, en todas las instancias de gobierno, sería mucho más factible la prevención y el control de los diversos casos de corrupción que se suceden en las altas esferas de gobierno. Por lo que se hace imprescindible dotar a los municipios de mejores normas jurídicas que propicien la participación ciudadana y permitan la incorporación de nuevos actores sociales locales.

Al respecto, Ovidio (2004: 53) plantea que "la incorporación de nuevos actores e instituciones sociales y la disponibilidad de normas jurídicas, que promuevan la diversidad de agentes sociales en los procesos participativos, más abiertos y menos tutelados, podrían ser la clave de una construcción socialista desde lo popular, con un sentido de mayor compromiso y efectividad".

Se refiere a actores que no formen parte de la vida tradicional de la isla: los trabajadores por cuenta propia, los trabajadores agrícolas privados sin vinculación estatal, los trabajadores del sector informal (oficios u otros trabajos privados de corto plazo no establecidos previamente por el Estado) y los empleados por el capital extranjero.

Además, éstos no son los únicos, puesto que también existen grupos sociales, que desde los años '80 adquirieron un peso relativamente destacado en la estructura social, como son los técnicos, los profesionales y los religiosos. Para estos nuevos actores, la diferencia radica en que precisamente como su actividad no responde a lo Estatal, el gobierno nacional no reconoce su vinculación a la sociedad civil, porque se apartan del tradicional control económico-social socialista.

Por otra parte, la normatividad jurídica, a la que ya hemos hecho alusión, es uno de los más importantes indicadores a tener en cuenta, no sólo por su inminente modificación en consonancia con las demandas de los territorios y el contexto histórico actual, sino además porque constituye el punto de partida para la concientización de los ciudadanos en el papel que les toca jugar, en relación al diseño del futuro del territorio en el que viven ${ }^{20}$.

Con el fin de lograr tales cometidos, se necesita de una mayor coordinación de acciones entre los actores locales para la solución de los problemas que afectan a las comunidades, como son la alimentación, el transporte, la construcción de viviendas e instalaciones con fines sociales, el ordenamiento territorial y el de los servicios generales

\footnotetext{
${ }^{20}$ Vid., Pastor, J. (2004.Gobernabilidad y Democracia: Los órganos del Poder Popular en Cuba.
} 
(comercio, gastronomía, educación, salud, cultura, entre otros) (Tejera, 2007).

Cuando se habla de integralidad entre las diversas dimensiones que se ponen de manifiesto en el desarrollo local, los analistas cubanos a los que estamos citando se refieren, en lo fundamental, a la incorporación de todas las áreas y a los aspectos a tener en cuenta para el diseño de buenas prácticas de políticas de desarrollo territorial, sin menoscabo del medio ambiente y teniendo en cuenta su sostenibilidad.

Así mismo, la consolidación de la identidad local, la manera de sentir el territorio, el medio favorable o no para la transformación desde y para la sociedad, son indicadores a no olvidar como catalizadores del desarrollo local según afirman prestigiosos investigadores como Rausell (2007). Es por ello que no es creíble ni posible que un actor que no se identifique con su territorio pueda implicarse positivamente en procesos políticos, sociales y económicos que redunden en el beneficio de éste. Por lo que ese deseado ambiente favorable, en la actualidad, se ve seriamente afectado por los desiguales niveles de desarrollo cultural de la población y el éxodo masivo del campo hacia las ciudades, entre otros elementos a tener en consideración.

\section{CONCLUSIONES}

Tras en el análisis de las relaciones entre el gobierno local y el desarrollo en los municipios de Cuba, vista desde la perspectiva histórica podemos afirmar que los obstáculos determinados por el entramado jurídico y por las relaciones de poder derivadas de la estructura política cubana dificultan la aplicación de las modernas teorías del desarrollo local. Ello se debe, sobre todo, a la centralización estatal de las funciones jurídicoeconómicas.

Coincidimos con estudiosos cubanos como Tejera, Guzón, Alonso, Caballero y Carnero, cuando señalan como contradicciones más significativas en la relación que existe entre el gobierno nacional y el gobierno municipal la no correspondencia entre las dinámicas aceleradas del desarrollo local y la lentitud del cambio de las estructuras políticas locales; la contradicción entre el gobierno nacional y las localidades por la limitada asignación de recursos para implementar políticas de desarrollo que respondan a las problemáticas del territorio, y la tensa contradicción entre el gobierno nacional y el gobierno local debido a la escasa capacidad de decisión de éste último y a las [poquísimas] competencias reales que se le atribuyen.

Realmente, en nuestra opinión, los márgenes asignados a los gobiernos municipales, junto a la incapacidad de éstos para utilizarloscon vistas a encontrar las sinergias necesarias para el desarrollo de su territorio, convierte a los gobiernos locales en meros entes representativos del Estado que no pueden incidir con la autonomía que sería deseable en sus propios territorios.

Aún en estas condiciones, el Estado dice intentar estimular un cambio positivo en la relación entre el gobierno y el desarrollo de las localidades, pero las estructuras locales del Poder Popular son ineficientes, no sólo por la complejidad burocrática que entrañan, sino por el alcance que se le otorga a las mismas. Unas estructuras que fueron creadas para la gestión y el diseño de planes y estrategias que impulsaran el desarrollo sostenible 
de las distintas zonas del país, y que supondrían, además, un nexo importante entre el gobierno nacional y la base, pero que contradictoriamente nunca han poseído la capacidad autónoma de implementar sus decisiones sin que medie antes la aprobación del gobierno nacional.

La utilización de los criterios teórico-metodológicos definidos por algunos académicos cubanos permite estudiar -aunque no de forma crítica e integral- la relación que existe entre el gobierno nacional y el gobierno municipal, a la vez que evidencia lo ineficiente de sus estructuras y de sus canales de comunicación de abajo-arriba y de arriba-abajo.

No obstante, conviene no olvidar que Cuba cuenta con un contingente de técnicos preparados que están en disposición de proporcionar alternativas de resolución o, cuanto menos, propuestas que reduzcan los altos costos sociales que se están padeciendo en el país.

Como ya apuntamos en un trabajo anterior ${ }^{21}$, existen investigaciones que demuestran que las universidades en la isla tienen la posibilidad de constituirse en elementos orientadores de políticas públicas en pos de sociedades mucho más justas, que enfrenten y superen la inequidad y la exclusión para alcanzar mayores niveles de educación y mejor calidad de vida. Tienen la posibilidad de convertirse en un actor proactivo que, junto a otros organismos de gestión del conocimiento, participen activamente en la elaboración de políticas de desarrollo local. Esas universidades están capacitadas y poseen las herramientas necesarias para la creación de una posible Alianza Universidad-Empresa-Estado dentro de sus regiones(Betancourt, 2015).

En tal sentido proponemosprofundizar en el conocimiento de ejemplos de buenas prácticas y modelos de alianzas estratégicas entre la universidad, las empresas y el Estado. Eso permitiría, muy probablemente, explotar las potencialidades que brindan éste tipo de nexos, en los que la ciencia teórica y la aplicada puedan ir en una misma dirección para dar respuesta a las problemáticas locales.

Otra conclusión nace de la confirmación de que los nuevos Lineamientos PolíticoEconómicos de actualización del modelo económico cubano apoyan -al menos en teoríael proceso de descentralización de las funciones municipales, y anuncian la creación de la necesaria alianza entre las universidades y la administración pública. Así se desprende, si lo entendemos bien, del discurso pronunciado por el Ministro de Educación Superior en el Palacio de las Convenciones el 10 de septiembre de 2014. Un breve discurso que constituye, sin duda, el reconocimiento Estatal a las necesidades y deficiencias del sistema de gobierno central, y apunta a las posibles soluciones a implementar para dar respuesta a una parte de los problemas que afronta el país. Se abre con ello la posibilidad de poner en práctica propuestas de buenas alianzas estratégicas que se correspondan con la realidad nacional.

Por otra parte, entendemos que en el caso de Cuba, apoyándonos en Noguera (2015), no es pertinente ni viable un proceso de descentralización acelerado y descontrolado en el que se menoscabe la autoridad del Estado como garante de los

\footnotetext{
${ }^{21}$ Las imprescindibles sinergias entre los diversos actores políticos y sociales en pos del desarrollo local en Cubaen Nueve Estudios Hispano-Cubanos sobre desarrollo Local.
} 
intereses comunes. Aun cuando estamos en presencia de un sistema centralizado -propio de los años '70- poco flexible para adaptarse el entorno, con una primacía de la planificación sectorializada frente a la territorial, en el que la inversión externa tiene mucho más valor que los potenciales endógenos de sus localidades, y en el que es evidente la primacía de los proyectos nacionales frente a los municipales, debemos tener en cuenta que las características propias del sistema socialista vigente no admite bruscos cambios descentralizadores.

Nos referimos fundamentalmente a que para establecer un adecuado tránsito de gobierno a gobernanza habría que crear -entre otros ítems- partenariados entre distintas organizaciones gubernamentales y no gubernamentales, lo que [visto desde la óptica imperante] sería entendido como una mella a la soberanía nacional y en el caso de la isla podría acarrear más perjuicio que beneficios.

Una descentralización acelerada entrañaría, además, la inconveniencia del llamado vaciamiento del Estado (Pike et allí, 2011). Se trata de esa fase en la que las principales funciones estatales se diseminan en beneficio de instituciones supranacionales. Como sabemos, esos procesos inciden cada vez más en los asuntos internos de los Estados implicados: está establecida la cesión de cada vez más importantes dosis de soberanía en función de intereses que pueden ser contradictorios con los nacionales.

Se trata entonces de lograr una mayor cohesión entre el Estado y las entidades locales, entre el gobierno nacional y los gobiernos municipales a través de un proceso de descentralización medido y repensado, pero que no redunde en un aparente otorgamiento de autonomía a los municipios, sino que por el contrario ésta sea real y efectiva. Una relación que se base en la confianza y en la sinergia entre los distintos actores implicados en el diseño y la implementación de las políticas de desarrollo. Se trata de hacer efectivas, a través de un sistema de participación democrática real y no dirigida para la toma de estas decisiones y de ofrecer garantías jurídicas suficientes para la exigencia de éstas a los gobernantes. Un sistema democrático en el que debe primar la institucionalidad y los canales de comunicación y participación con y de la ciudadanía.

Entendemos que, en el caso de Cuba, se lograría un efectivo desarrollo de políticas locales que beneficiarían a sus ciudadanos, fundamentalmente -aunque sin desestimar ni desatender los ítems antes señalados- con el otorgamiento de competencias autónomas a la municipalidad,como principio imprescindible para la puesta en marcha de soluciones a las problemáticas territoriales en materia de desarrollo económico, social y cultural.

\section{BIBLIOGRAFÍA}

Alburquerque, F. 1999. Manual del agente del desarrollo local. Diputación de Barcelona, España.

Alcázar, J. 2003. "De la Alianza para el Progreso a la democratización y la desmilitarización" en Historia Contemporánea de América (Alcázar, J., Tabanera, N. y Santacreu J. (coord.)) Valencia, Universidad de Valencia, pp. 277-279. 
Alcázar, J. y López, S. 2013. “Fidel Castro, cuatro fases de un liderazgo inacabado" en Araucaria, Revista Iberoamericana de Filosofía, Política y Humanidades, año 15, no. 30, Segundo semestre 2013, Sevilla, Estugraf, p. 15.

Álvarez, F. 2008.La dimensión cultural del desarrollo local. Una experiencia en el oriente cubano. (Tesis en opción al Grado Científico de Doctor en Ciencias Sociológicas), Santiago de Cuba, Universidad de Oriente, p. 67.

Arias, H. 1995. La comunidad y su estudio, La Habana, Editorial Pueblo y Educación.

Armstrong, H. y Taylor, J. 2000.Regional Economics and Policy, (3erd ed.), Oxford, Blackwell.

Betancourt, I. 2015. "Las imprescindibles sinergias entre los diversos actores políticos y sociales en pos del desarrollo local en Cuba" en Nueve estudios hispano-cubanos sobre desarrollo local (Betancourt, I. y Ferrándiz, A. (eds.)), Valencia, Publicacions de la Universitat de València, pp. 105-122.

Boisier, S. 2003. "El desarrollo territorial a partir de la construcción de capital sinergético", disponible en http://www.eumed.net

Boisier, S. 2003. "¿Y si el desarrollo fuera una emergencia sistémica?" en: Desarrollo Humano Local. Antología preparada para el diplomado de Facilitadores del Desarrollo Local, Trabajo Decente y Enfoque de Género, La Habana, Cátedra UNESCO/Universidad de La Habana/PNUD/OIT/PDHL.

Boisier, S. 2005. “¿Hay espacio para el desarrollo local en la globalización?” en Revista de la Comisión Económica para América Latina (C.E.P.A.L.), no. 86, Santiago de Chile, Publicaciones de Naciones Unidas.

Boisier, S. 2005. “Desarrollo (local) ¿De qué estamos hablando?"disponible en http://www.cedet.edu.ar/sitio/administracion/agenda/boisier.pdf

Caballero, M. y Yordi, M. (2004.El trabajo comunitario: alternativa cubana para el desarrollo social, Camagüey, Editorial Ácana, Ediciones Universidad de Camagüey, pp. 118-119.

Cantón, J. y Silva, A. 2009. Historia de Cuba. Liberación nacional y socialismo (1959-1999), La Habana, Pueblo y Educación.

Espina, M. 2006. "Apuntes sobre el concepto de desarrollo y su dimensión territorial” en: Desarrollo localenCuba (Guzón, A. (coord.)), La Habana Editorial Academia.

Fleitas, R. y Rojas, F. (2005.Desarrollo Humano Local, PNUD/Cuba, disponible en http://www.yorku.ca/ishd/CUBA.LIBRO.06/DEL/INTRODUCCION.pdf, p. 13

Fuentes, B. (2010.La gestión de conocimiento en las relaciones académico-empresariales. Un nuevo enfoque para analizar el impacto del conocimiento académico, (Tesis doctoral), Valencia, Universidad Politécnica.

García, J. 1949.La Municipalidad holguinera, su creación y su desenvolvimiento hasta 1799, Manzanillo, Editorial El Arte, pp. 68-69, 105-107.

García, J. 2004. Gobernabilidad, Democracia y una nueva ciencia política, La Habana,Editorial de Ciencias Sociales.

Guzón, A. 2004. "Los municipios y sus potencialidades para el desarrollo local" en CIPS. Boletín electrónico, año 1 no.3 nov, La Habana, pp. 67-85.

Guzón, A. 2006. "Estrategias municipales para el desarrollo" en Desarrollo local en Cuba (Guzón, A (coord.)), La Habana, Editorial Academia, pp. 64-90. 
Guzón, A. 2006.Desarrollo local en Cuba. Retos y perspectivas, La Habana, Editorial Academia, pp. 15-21.

Hernández, A. 1998. "Cuba en los 90. La descentralización como alternativa a la crisis económica" en Desarrollo local y participación en el contexto urbano (Dávalos, R. (Comp.), La Habana, Universidad de La Habana, pp. 32, 137-153.

Hernández, A. 2004. “¿De desarrollo local qué estamos hablando?” en Desarrollo Humano Local, PNUD/Cuba, p.189.

Hernández, F. 2008.Concepción sociocultural de la gestión participativa de los grupos de trabajo comunitario integrado. Un estudio teórico - práctico en el contexto holgüinero, (Tesis en opción al Grado Científico de Doctor en Ciencias Sociológicas), Santiago de Cuba, Universidad de Oriente,

Hernández, J. 2006. "La ciencia y la tecnología como factores de desarrollo. El espacio local" en: Desarrollo local en Cuba (Guzón, A. (coord.), La Habana, Editorial Academia, pp. 42, 175-186.

Hernández, R. 1998. "¿Hacia una nueva sociedad socialista? Cambios, crisis y configuraciones sociales en Cuba" en RevistaNueva Sociedad, \# 157, Septiembre Octubre de, Caracas, Venezuela, pp. 137-153.

Instituto de Planificación Física, 1999. Análisis y Cartografía de la Vulnerabilidad a la Inseguridad Alimentaria, Instituto de Planificación Física/Programa Mundial de Alimentos, La Habana.

Labrada, C. 2008.Desarrollo local. Un estudio de caso en el municipio "Rafael Freyre", provincia de Holguín, (Tesis de doctorado), Santiago de Cuba, Universidad de Oriente.

Machado, D. 2004. “¿Hacia dónde va la Sociedad Cubana?” en Revista Cuba Socialista, Edición Digital, disponible en http://www.cubasocialista.cu

Márquez, R. 2006.Cubanología y Revolución, La Habana, Ciencias Sociales.

Max, M. 2005.Desarrollo a Escala Humana: Conceptos, Aplicaciones y Reflexiones. Guadalajara, Universidad de Guadalajara.

Meriño, M. 2001.Gobierno Municipal y Partidos Políticos en Santiago de Cuba (18981912), Santiago de Cuba, Ediciones Santiago.

Noguera, J. 2009. "Pensamiento y planificación estratégica. Definición e implementación de estrategias de desarrollo" en Gestión y promoción del desarrollo local, (Noguera, J., Pitchard, M. y Esparcia, J. (eds.)), Valencia, Publicacions de la Universitat de València.

Noguera, J. 2015. "Metodologías de intervención para un desarrollo sostenible: concertación y planificación" en Nueve estudios hispano-cubanos sobre desarrollo local (Betancourt, I. y Ferrándiz, A. (eds.)), Valencia, Publicacions de la Universitat de València, pp. 18-26.

Noguera, J. y Ferrer, V. 2008. “Análisis de políticas con impacto en la perifericidad espacial y no espacial" en Nuevos factores de desarrollo territorial (Noguera, J. y Esparcia, J. (eds.)), Valencia, Publicacions de la Universitat de València.

Noguera, J., y Esparcia, J. 2008. “Aspectos metodológicos: estructura de la investigación” en Nuevos factores de desarrollo territorial (Noguera, J., y Esparcia, J. (eds.), Valencia, Publicacions de la Universitat de València. 
Pichardo, H. 1992.Documentos para la Historia de Cuba, La Habana, Ciencias Sociales, pp. $12,75$.

Pichardo, H. 2000.Documentos para la Historia de Cuba, La Habana, Ciencias Sociales, pp. 75-101.

Pike, A., Rodríguez, A. y Tomaney, J. 2011.Desarrollo local y regional. Valencia, Publicacions de la Universitat de València, pp. 52, 176-183.

PNUD 1999.Informe de Desarrollo Humano. Nueva York.

PNUD 1999.Investigación sobre Desarrollo Humano y Equidad en Cuba, La Habana, Caguayo S. A.

PNUD 2004.Informe de Desarrollo Humano, New York.

PNUD Cuba 2005.Desarrollo Humano Local, disponible en http://www.yorku.ca/ishd/CUBA.LIBRO.06/DEL/INTRODUCCION.pdf, p. 189.

Pollard, S. 1981.Peaceful Conquest: The industrialization of Europe, 1760-1970, Oxford: Oxford University Press.

Rausell, P. 2007.Cultura.Estrategia para el Desarrollo Local. Cultura y desarrollo, Valencia, Editorial del Instituto Interuniversitario de Desarrollo Local de la Universidad.

Ravenet, M. 2002.Espacio y territorio en los estudios sociológicos en Cuba, (Tesis doctoral), La Habana, Universidad de La Habana.

Rodríguez, N 2004. “Educación Ambiental y Desarrollo Local. Una introducción a la discusión teórica", en Revista Santiago, Santiago de Cuba, Universidad de Oriente.

Rodríguez, N. 2003.Educación Ambiental y Desarrollo Local: Un binomio de la contemporaneidad, (Tesis de Diplomado para Facilitadores del Desarrollo Local, Desarrollo Humano y Trabajo Docente), disponible en el Centro de Estudios Cuba Caribe "José Antonio Portuondo", Facultad de Ciencias Sociales, Santiago de Cuba, Universidad de Oriente.

Romero, J. y Boix, A. (eds.) 2015.Democracia desde abajo. Nueva agenda para el gobierno local. Valencia, Publicacions de la Universitat de València.

Tejera, P. 2007.Aproximación a la relación entre gobierno local y desarrollo local. Estudio para la sociedad cubana actual, (Tesis de doctorado), Santiago de Cuba, Universidad de Oriente, pp. 35, 42, 43.

Vaillant, N. y Hechavarría, M. 2015. "Cooperativismo y desarrollo local. Una mirada desde la política económica y social de Cuba" en Nueve estudios hispano-cubanos sobre desarrollo local (Betancourt, I. y Ferrándiz, A. (eds.)), Valencia, Publicacions de la Universitat de València.

Valdés, O. 2007.La Revolución Cubana. Premisas económicas y sociales,La Habana, Ciencias Sociales.

Vázquez, A. 1999.Desarrollo, redes e innovación. Lecciones sobre desarrollo endógeno, Madrid, Pirámide.

Vázquez, A. 2000. “Desarrollo económico local y descentralización: aproximación a un marco conceptual", en Comisión Económica para América Latina y el Caribe (CEPAL) LC/R.1964, Santiago de Chile.

Venegas, A. 1932.Los municipios cubanos a través de la jurisprudencia. La Habana, Jesús Montero Editor. 
Viciano, R. 2000. “Cuba: un balance de las reformas jurídicas en la década de los 90" en América Latina: Literatura e Historia entre dos finales de siglo (Alcázar, J. y Mattalia, S. (coord.)), Valencia, Edit. Centre d’Estudis Polítics i Socials (CEPS), p. 85 